\title{
Correction to: Completion, Čech and Local Homology and Cohomology
}

\section{Correction to:}

\section{P. Schenzel and A.-M. Simon, Completion, Čech and Local}

\section{Homology and Cohomology, Springer Monographs}

in Mathematics, https://doi.org/10.1007/978-3-319-96517-8

In the original version of the book, the following corrections have to be incorporated:

In the copyright page of front matter, Anne-Marie Simon's affiliation was published wrongly as "Service de Geometrie differentielle" has been updated as "Service de Géométrie différentielle".

Spacing corrections and corrections in equations and cross-citations were published with errors throughout the book have been corrected.

Incorrect arrow mark has been updated in Appendix (Book Backmatter).

The original version of the book was revised: Author corrections have been incorporated. The correction to the book is available at

https://doi.org/10.1007/978-3-319-96517-8 